
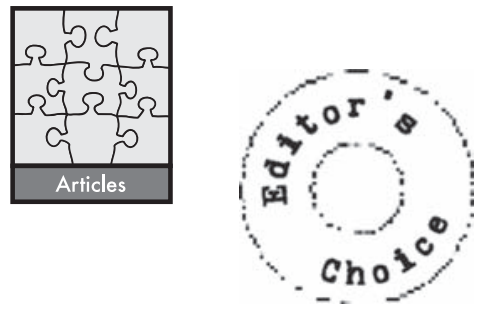

Journal of Avian Biology 46: 332-341, 2015

doi: $10.1111 /$ jav.00701

(C) 2015 The Authors. Journal of Avian Biology (c) 2015 Nordic Society Oikos Subject Editor: Toni Laaksonen. Editor-in-Chief: Jan-Åke Nilsson. Accepted 15 January 2015

\title{
Seasonal mortality and sequential density dependence in a migratory bird
}

\author{
Eldar Rakhimberdiev, Piet J. van den Hout, Maarten Brugge, Bernard Spaans and Theunis Piersma \\ E. Rakhimberdiev (eldar.rakhimberdiev@nioz.nl), P. J. van den Hout, M. Brugge, B. Spaans and T. Piersma, Dept of Marine Ecology, NIOZ \\ Royal Netherlands Inst. for Sea Research, PO Box 59, NL-1790 AB, Den Burg, Texel, the Netherlands. ER also at: Dept of Vertebrate Zoology, \\ Biological Faculty, Lomonosov Moscow State Univ., RU-119991, Moscow, Russia, and Dept of Ecology and Evolutionary Biology, Cornell Univ., \\ Corson Hall, Ithaca, NY 14850, USA. TP also at: Chair in Global Flyway Ecology, Animal Ecology Group, GELIFES, Univ. of Groningen, PO \\ Box 11103, NL-9700 CC Groningen, the Netherlands.
}

\begin{abstract}
Migratory bird populations may be limited during one or more seasons, and thus at one or more places, but there is a dearth of empirical examples of this possibility. We analyse seasonal survival in a migratory shellfish-eating shorebird (red knot Calidris canutus islandica) during a series of years of intense food limitation on the nonbreeding grounds (due to overfishing of shellfish stocks), followed by a relaxation period when destructive harvesting had stopped and food stocks for red knots recovered. For the estimation of seasonal survival from the $15 \mathrm{yr}$-long near-continuous capture-resight dataset, we introduce a 'rolling window' approach for data exploration, followed by selection of the best season definition. The average annual apparent survival over all the years was $0.81 \mathrm{yr}^{-1}$. During the limitation period, survival probability of adult red knots was low in winter $\left(0.78 \mathrm{yr}^{-1}\right)$, but this was compensated by high survival in summer $\left(0.91 \mathrm{yr}^{-1}\right)$. During the relaxation period survival rate levelled out with a winter value of $0.81 \mathrm{yr}^{-1}$ and a summer survival of $0.82 \mathrm{yr}^{-1}$. The fact that during the cockle-dredging period the dip in survival in winter was completely compensated by higher survival later in the annual cycle suggests sequential density dependence. We conclude that seasonal compensation in local survival (in concert with movements to areas apparently below carrying capacity) allowed the islandica population as a whole to cope, in 1998-2003, with the loss of half of the suitable feeding habitat in part of the nonbreeding range, the western Dutch Wadden Sea. As a more general point, we see no reason why inter-seasonal density dependence should not be ubiquitous in wildlife populations, though its limits and magnitude will depend on the specific ecological contexts. We elaborate the possibility that with time, and in stable environments, seasonal mortality evolves so that differences in mortality rates between seasons would become erased.
\end{abstract}

Predicting responses of wildlife populations to habitat change and loss requires an understanding of the regulation of these populations (Faaborg et al. 2010). It is widely accepted that density dependence with a negative feedback loop between successive life-cycle events is a key regulator (see Herrando-Pérez et al. 2012 for a review). Two periods of the life-cycle are considered important for natural regulation of populations: 1) reproduction during the breeding season and 2) overwinter survival; the two may act sequentially through density-dependent regulation (Fretwell 1972). In seasonally migrating animals interactions between the summer and winter seasons not only connect distinct events in time, but also in space. For example, populations of migrant birds represent systems that involve annual movements between the areas of reproduction and survival, i.e. between the breeding and wintering areas (Alerstam and Högstedt 1982, Alerstam 1990).

Historically, the question how migratory birds respond to changes in the seasonal sequence of environments used, started with an exploration of whether the seasonal elimination of animals ('harvest', which is mostly densityindependent) during one season would lead to compensation in the form of higher survival later on (Anderson and Burnham 1976, Burnham and Anderson 1984, Kokko and Lindström 1998, Boyce et al. 1999). This research showed that the density-independent mortality induced by harvests may indeed be completely compensated by density-dependent regulation during the next season. If densityindependent mortality is indeed compensated, then populations should also compensate density-dependent losses during previous population-limiting season. The first theoretical model exploring the relevant responses for a migratory bird population was developed by Dolman and Sutherland (1995). The model analysed consequences of loss of winter habitat and showed that compensation will happen (at least partially) when the population is limited at the step where it has lost habitat and at the next (compensating) step. Thus, the population must have at least two sequential density-dependent regulators in order for it to compensate for habitat loss. Runge and Marra (2005) additionally incorporated seasonal 
carry-over effects, i.e. the individual level seasonal interactions (Norris et al. 2004, Norris 2005), and concluded that such carry-over effects weaken the density-dependent compensation. Both these population model exercises agree that a prevalence of either wintering- or breeding-ground limitation depends on population parameters such as the strength and shape of density dependence at each season, the densities of animals, and adult and juvenile survival; these are all parameters that have to be estimated in real populations. However, their estimation is daunting and this may explain the scarcity of empirical studies (but see Schaub et al. 2012, Lok et al. 2013, Oppel et al. 2014, Tempel et al. 2014).

Starting with Fretwell's two-season model (Fretwell 1972), there seem to be agreement on the assumption that reproduction takes place only in summer (which is generally true for iteroparous animals), whereas mortality only happens in winter (which is unlikely ever to be true). Current statistical methods allow the estimation of survival in wild animals not only on an annual, but also on a seasonal basis, so one might test whether sequential density dependence operates at the level of seasonal survival. In this contribution we have asked ourselves whether there is a sequential density dependence in the survival rates of a migratory bird throughout the year, and if there is, then how and where it could operate?

Equilibrium populations under stable conditions do not show changes in density and thereby make it impossible to assess density dependence. One of the solutions is to study a fast growing population (Lok et al. 2013). Another possibility, adopted here, is to focus on a population during a period of serious limitation. We analysed the capture-resight data of the islandica population of red knots Calidris canutus (hereafter 'knot') during a series of years of food shortage on the wintering grounds followed by a period of recovery of these food stocks. These knots breed in the High Arctic of Greenland and north-eastern Canada and winter in coastal areas in north-western Europe (Davidson and Wilson 1992, Piersma et al. 2005, Buehler and Piersma 2008, Fig. 1). Some knots return from the tundra breeding grounds to Europe in nonstop flights, whilst others first stage in Iceland (Dietz et al. 2010). During the 'winter' season, which lasts from early August until late April, knots remain in coastal areas in the UK, the Netherlands, France, Germany and Denmark (Davidson 2002, Quaintenne et al. 2011). Immediately after arrival on the wintering grounds knots undergo a complete feather moult (Boere 1976, Dietz et al. 2013). In May, en route to the breeding grounds, knots stop to refuel either in northern Norway or in Iceland (Davidson and Wilson 1992, Wilson et al. 2009).

The data were collected from 1998 to 2013 and we distinguished two periods. From 1998 to 2002, in the core study area, the western Dutch Wadden Sea, knots experienced the effects of destructive dredging for edible cockles Cerastoderma edule (Piersma et al. 2002, Kraan et al. 2007, 2010, Eriksson et al. 2010). Mechanical cockle-dredging led to a decline of the numbers of red knots using this area of at least 25\% during five years (van Gils et al. 2006, Kraan et al. 2009). In 2003 mechanical cockle-dredging stopped, after which food stocks began to recover (Compton et al. 2013, W. Bodnar et al. pers. comm.). Here we consider the temporary loss of up to $55 \%$ of the intertidal habitat suitable for feeding

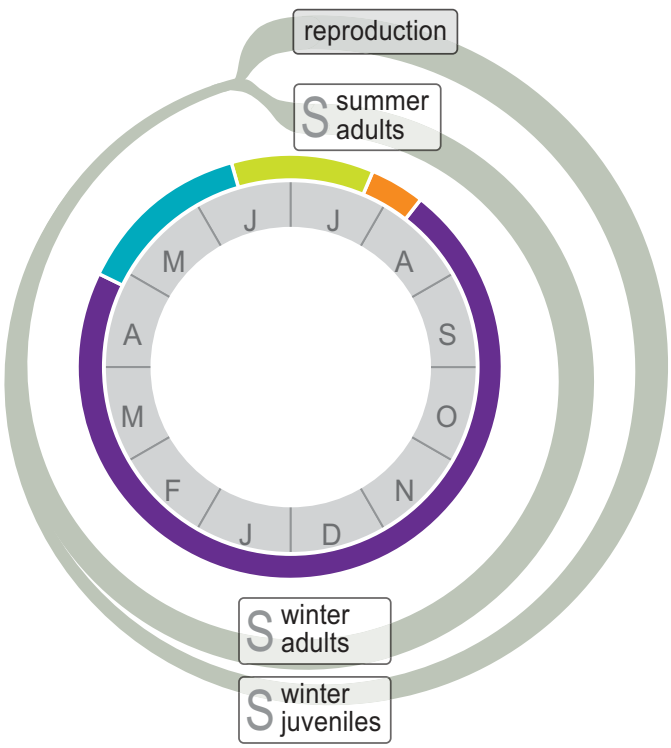

Figure 1. Annual cycle of the islandica red knot together with the regulating demographic parameters: survival $(S)$ of adults, reproduction (production of young) and their subsequent survival.

in 1998-2002 (Kraan et al. 2009), followed by recovery, as a large scale experiment to test the presence of sequential density-dependent regulation in a migrating bird.

If a population of red knots experiences sequential density dependence in survival rates, we should observe the following. During the period of intense-cockle dredging they would experience severe limitation after arrival on the wintering grounds to then die or emigrate (this will be the first density-dependent event). With the loss of many individuals in winter, the population will come to the summer season in significantly lower numbers. Thus, if the population is regulated also in summer, there will be lower density-dependent pressure (second density-dependent event), which will make survival during summer season high. Overall apparent survival may thus actually be unaffected by shellfish-dredging if it happens within certain boundaries of seasonal compensation.

The existence of seasonal compensation and sequential density-dependence in knot will thus be characterized by the following predictions: 1) there will be a densitydependent response in lower apparent survival in winter during the dredging period; 2) density dependence in summer will compensate for winter loss by a higher apparent survival during the limitation period; 3) the red knot population is likely to show no difference in annual apparent survival rate between the limitation and relaxation periods.

\section{Methods}

\section{Capture-resight data}

We individually colour-ringed knots in the western Dutch Wadden Sea $\left(53.25^{\circ} \mathrm{N}, 5.25^{\circ} \mathrm{E}\right)$ in $1998-2013$ (Table 1). Birds were captured using mist nets placed in the flight lines towards or from high-tide roosts mostly around the islets Griend and Richel. We made efforts to resight marked individuals throughout the entire non-breeding season 
Table 1. Distribution of adult red knot captures and unique individuals resighted across years and months (pooled over years) of the study.

\begin{tabular}{|c|c|c|c|c|c|c|c|c|c|c|c|c|c|c|c|c|}
\hline Year & '98 & ‘99 & ‘00 & '01 & ‘02 & `03 & ‘04 & ‘05 & ’06 & ‘07 & `08 & ‘09 & $' 10$ & $' 11$ & $' 12$ & 13 \\
\hline Captured & 47 & 161 & 538 & 123 & 7 & 3 & 85 & 574 & 558 & 524 & 264 & 60 & 47 & 161 & 538 & 123 \\
\hline \multirow[t]{4}{*}{ Resighted } & 235 & 270 & 191 & 0 & 0 & 0 & 46 & 473 & 450 & 694 & 89 & 0 & 235 & 270 & 191 & 0 \\
\hline & & Month & Jul & Aug & Sept & Oct & Nov & Dec & Jan & Feb & Mar & Apr & May & Jun & & \\
\hline & & Captured & 55 & 328 & 306 & 392 & 191 & 60 & 46 & 155 & 487 & 97 & 7 & 1 & & \\
\hline & & Resighted & 45 & 328 & 232 & 546 & 4 & 0 & 235 & 192 & 137 & 0 & 0 & 0 & & \\
\hline
\end{tabular}

(including times of migration and wintering), and obtained resightings by approaching foraging flocks on the intertidal mudflats during times of low water. Nevertheless, resighting probabilities tended to be low as the finding and reading of individual colour-ring combinations on the mudflats is hard work, especially in the Wadden Sea where the birds occur very widespread over the extensive intertidal flats habitat far away from human infrastructure (Piersma et al. 1993). Only data on resightings from the western Dutch Wadden Sea were included in the analysis.

Data limitations forced some restrictions on the complexity of the capture-recapture models used. First, because we captured mostly adults, and because there are reasons to believe that juveniles have lower survival rates than older birds (Leyrer et al. 2013), we excluded birds captured in their first year of life from the analyses. Second, because male and female knots are similar in body size (Baker et al. 1999), and as in this subspecies and in the partially co-occurring canutus subspecies there were no sex differences in annual survival rate (resp. Brochard et al. 2002, Leyrer et al. 2013), we pooled the data for the sexes. In total 2448 colour-marked birds were seen 4546 times afterwards (Table 1).

\section{Annual survival rate estimation}

For the estimation of annual and seasonal apparent survival rates from the life-encounter tables we used program MARK (White and Burnham 1999) through the RMark interface (function mark(), Laake 2013) in R (ver. 3.0, R Core Team) and the package 'marked' in R (function $\operatorname{crm}($ ), Laake et al. 2013). For the estimation of annual apparent survival $(\Phi)$ of adult knots, we used a Cormack-Jolly-Seber (CJS) model (Lebreton et al. 1992) in which the boundary between years was set at 15 July, a time when only nonbreeding juvenile red knots are present in the study area (Dietz et al. 2013).

Resighting $(P)$ and apparent survival $\Phi$ probabilities were treated as functions of time since marking (TSM), with or without an additive effect of year (Table 2). We included the TSM effect with two classes - $\Phi^{1}$ and $\Phi^{2+}$ - to account for the bias of continuous capture and resighting efforts (see below). Time-dependent variation among years was compared with a time-independent and 'full period dependence' design (Table 2). Because of the primary interest in two time periods (during and after the period of mechanical cockledredging) in the 'full period dependence' we combined years of study into three periods: 1) the period of dredging (1999-2002) - 'limitation period', 2) the relaxation period (2003-2010), and 3) recent years (2011-2013). In the present analysis we do not consider estimates from the last period for the simple reason that terminal estimates of survival are usually biased when resighting rates are low (Rakhimberdiev unpubl. based on analysis of simulated data).

In order to test the third prediction (no change in annual apparent survival rate from time periods), we needed to test the difference between specifically the dredging and the relaxation period. Support for a difference was estimated by comparison of AIC weights of the two following models. The first has all three periods (dredging, relaxation and recent, model 2 in Table 2) and the second had first two periods combined (dredging-relaxation and recent, model 3 in Table 2). Model weights and 95\% confidence intervals were corrected for overdispersion level of 1.11 ( $\pm 0.06 \mathrm{SE}$ ), estimated by a median c-hat test for the fully time-dependent model (model 1 ) in Table 2 in program MARK.

\section{Exploratory analysis of seasonal survival rate}

The otherwise straightforward capture-recapture analysis of seasonal survival was hindered by the following: 1) our continuous colour-marking and resighting efforts provided a direct violation of the instantaneous sampling period assumption in CJS and related models (Lebreton et al. 1992), 2) the resighting probabilities in our study were low, and 3) there are no distinct borders between seasons as knots remain in the Wadden Sea throughout the 10-month winter period. The issues of a continuous sampling and low recapture rates can cause biased estimates of demographic parameters

Table 2. Models of yearly apparent survival of islandica red knot. Note: time since marking (TSM) class has two levels - 'first year after marking' and 'other years'. The results are adjusted for overdispersion of 1.11 (see 'Analysis'). a Deviance = 1326.5; b Quasi corrected Akaike information criterion $\left(\mathrm{QAIC}_{\mathrm{c}}\right)=9353.5$.

\begin{tabular}{|c|c|c|c|c|c|c|}
\hline \multirow{2}{*}{$\frac{\text { Model }}{1}$} & \multicolumn{2}{|c|}{ Description } & \multirow{2}{*}{$\frac{K}{32}$} & \multirow{2}{*}{$\frac{\Delta \text { deviance }}{0^{\mathrm{a}}}$} & \multirow{2}{*}{$\frac{\Delta \mathrm{QAIC}_{\mathrm{c}}}{0^{\mathrm{b}}}$} & \multirow{2}{*}{$\frac{\text { Model weight }}{0.87}$} \\
\hline & $\Phi(\sim$ TSMclass + year $)$ & $P(\sim$ TSMclass + year $)$ & & & & \\
\hline 2 & $\Phi(\sim$ TSMclass + 3_periods $)$ & $P(\sim$ TSMclass + year $)$ & 20 & 29.3 & 5 & 0.07 \\
\hline 3 & $\Phi(\sim$ TSMclass + 2_periods $)$ & $P(\sim$ TSMclass + year $)$ & 19 & 32 & 5.66 & 0.05 \\
\hline 4 & $\Phi(\sim$ TSMclass $)$ & $P(\sim$ TSMclass + year $)$ & 18 & 38.5 & 10.2 & 0.006 \\
\hline 5 & $\Phi(\sim$ TSMclass + year $)$ & $P(\sim$ TSMclass $)$ & 18 & 161.7 & 133.32 & 0 \\
\hline 6 & $\Phi(\sim$ TSMclass $)$ & $P(\sim$ TSMclass $)$ & 4 & 291.5 & 235 & 0 \\
\hline
\end{tabular}


(Lebreton et al. 1992), as under a continuous capturerecapture regime, with mortality happening on a daily basis, the survival estimates of marked individuals will be overestimated during the first 'season' after marking because none of the animals of this group were marked at the start of the season. The average real time of exposure to mortality for this season will always be smaller than the length of the season and can potentially reach zero if all individuals were marked only at the very end of the season. This violates the CJS assumption that all individuals are equally exposed to mortality throughout a time interval. To achieve unbiased estimates, we use a time since marking model design with two 'age' classes, which will give unbiased estimates for the second age class. Even when based on whole year intervals, yearly resighting rates were estimated as $0.26 \pm 0.01$ (value \pm SE for second TSM class - M2+from model 3 in Table 2). Dividing the year into two half-year seasons makes the seasonal resighting rate approximately 0.14 . This is low, and the use of even shorter seasons will make model estimation almost impossible (O'Brien et al. 2005). This left us the single option of estimating 'seasonally' pooled survival rates over half a year.

Environmental conditions in the Wadden Sea (weather, food and predation danger: Piersma 2012, Dietz et al. 2013) will vary continuously and gradually across the 9-10 months winter stay, such that there is no distinct border between 'seasons'. If there were two distinct seasons the typical approach would be to pool captures and resightings per season (Hargrove and Borland 1994), but in case of continuous capture-recapture data, the date at which to put the boundary while pooling is arbitrary. We generalized the approach of Hargrove and Borland and introduced a rolling boundary between seasons to make pooled estimates in a rolling window with a length of six months (Fig. 2). The aim of the 'rolling window approach', which can be considered a special case of local regression (Cleveland 1979), was to explore the distribution of mortality within a year. We rolled two boundaries six month apart from each other with a step of $10 \mathrm{~d}$ that gives 19 possible positions of two seasons within a year, and consequently 19 slices to be analyzed. For each boundaries position, captures and resights were pooled and the following CJS model was estimated.

As for the annual survival model, for the seasonal survival model the same 'full period dependence' in apparent survival was used. In addition to three periods (limitation, relaxation and recent), the CJS model had two seasons and two TSM classes: $\Phi(\sim$ TSMclass + period $\times$ season $) P(\sim$ time $)$. To estimate the model, we had to use the simulated annealing optimization routine in MARK in some of the slices. As the package 'marked' was able to optimize models with ADMB (Fournier et al. 2012), it was $>10$ times faster than MARK. One out of 19 slices failed to converge in either MARK or 'marked' and was excluded from the results. The rolling window approach allowed us to determine the best boundaries between seasons by comparing the AICc. These boundaries were used then to test first and second predictions.

\section{Model comparison for the selected seasons}

For the boundaries selected by the rolling-window approach we ran a set of models allowing specific comparisons.

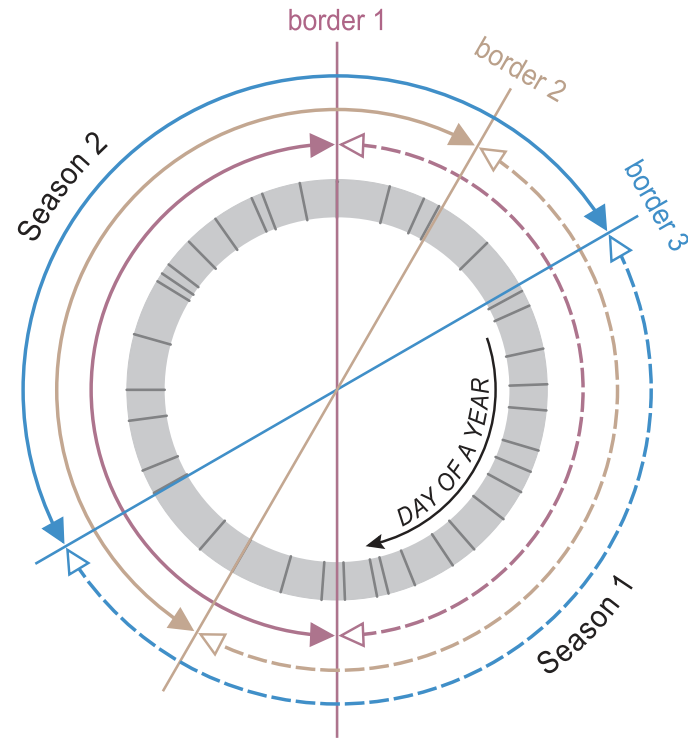

Figure 2. Demonstration of a 'rolling' (in this case half-yearly) time-window as it is used for exploratory analysis of seasonal survival in populations that are continuously monitored. Capture and resighting occasions (the black stripes in the inner circle) are grouped by a moving border that creates two, six-month intervals (Season 1 and Season 2). A separate analysis is conducted for each border position. In the current analysis the border was shifted $10 \mathrm{~d}$ between slices, thus making 19 slices a year.

Detailed descriptions of the eight different model structures for apparent survival are presented in Table 3. The recapture probability was modelled with minimal restrictions as fully time-dependent with an additive effect of TSM class. The results from the model runs were adjusted for the overdispersion of $1.057 \pm 0.005$, estimated for the model M1 by median c-hat test in program MARK.

For tests of the specific biological hypotheses we have followed the logic of multi-model inference (Burnham and Anderson 2002). The second prediction (winter apparent survival is lower during the dredging period then during

Table 3. Model design for seasonally pooled data. Circles illustrate potentially estimable parameters. Connected circles means shared parameters. For example model A is fully-period dependent model, model B assumes no difference between winter and summer survival during the dredging period whereas model D assumes no difference in summer survival between dredging and relaxation periods.

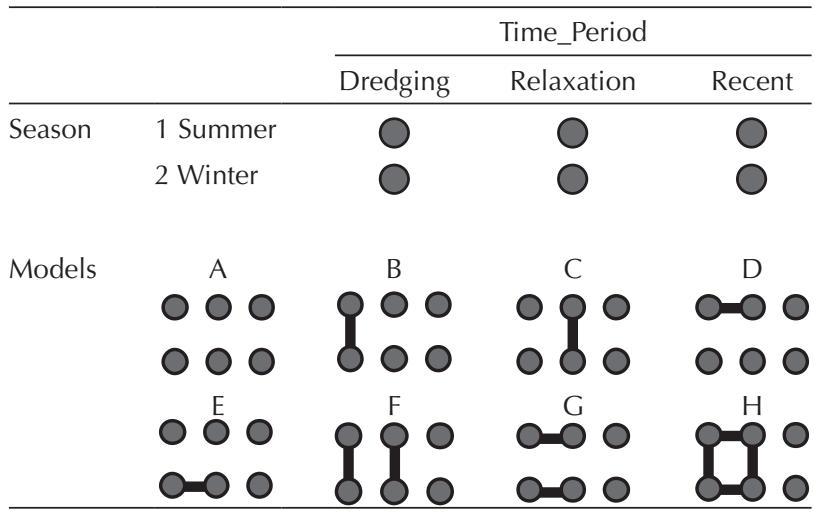


the relaxation period) was evaluated by the estimated evidence ratio of models with different parameters for dredging and relaxation periods for winter survival (see models A, B, C, D, and F in Table 3) over the rest of the models (E, G, and $\mathrm{H})$. Note that ideally, relative variable importance should be estimated from the balanced set of models having equal amount of models with and without variable of interest (Burnham and Anderson 2002). In order to normalize estimated evidence ratios from our imbalanced set of models ( 5 versus 3 ), we divided the cumulative weights by the number of models to get an averaged weight per model (Evidence ratio $=\frac{\sum A, B, C, D, F}{\sum E, G, H} \times \frac{3}{5}$; Kittle et al. 2008).

The third prediction (higher summer apparent survival during dredging versus relaxation period) was tested in the same manner by dividing the sum of importance weights for models A, B, C, E, F by the sum of weights for D, G and $\mathrm{H}$. Tests of some additional hypotheses may be done under the same framework. For example, we also estimated support for the hypotheses that apparent survival was different between winter and summer during a) dredging period Evidence ratio $=\frac{\sum A, C, D, E, G}{\sum D, E, H} \times \frac{3}{5}$ and b) and relaxation period Evidence ratio $=\frac{\sum A, B, D, E, G}{\sum C, F, H} \times \frac{3}{5}$.

\section{Results}

\section{Annual survival estimates}

Mean annual resighting rate was $0.26 \pm 01 \mathrm{yr}^{-1}$. The mean annual apparent survival of red knots was $0.81 \pm 0.01 \mathrm{yr}^{-1}$ (mean \pm SE, model 4, Table 2). However, as the fully timedependent model had a weight of 0.87 (Table 2), there was overwhelming support for annual survival variation between years. During the limitation period (1999-2002) annual apparent survival was $0.85 \pm 0.02 \mathrm{yr}^{-1}$ and during relaxation it became slightly lower $0.81 \pm 0.01 \mathrm{yr}^{-1}$. This difference had almost no support in the data: $\triangle \mathrm{AICc}$ between models 2 and 3 in Table 2 was only 0.66 . Thus, our prediction that seasonal compensation masks food limitation was supported by data.

\section{Seasonal survival estimates}

The exploratory analysis with the rolling window approach showed that mortality of adult knots during the period of intense cockle-dredging was not evenly distributed over the year (Fig. 3). The six-month rolling average survival was highest from February to July, the time of year that includes two migration episodes and the breeding season. Survival was lowest in August-January. In the period after the mechanical cockle-dredging had stopped, seasonal survival rates became rather constant (Fig. 3). The selection of the best definition of season by AICc values of the fully period-dependent model highlighted the model with boundaries at 27 June and 27 December (note that these dates are boundaries for data pooling but at the same moment centres for the survival estimates by CJS model). The remaining analyses were

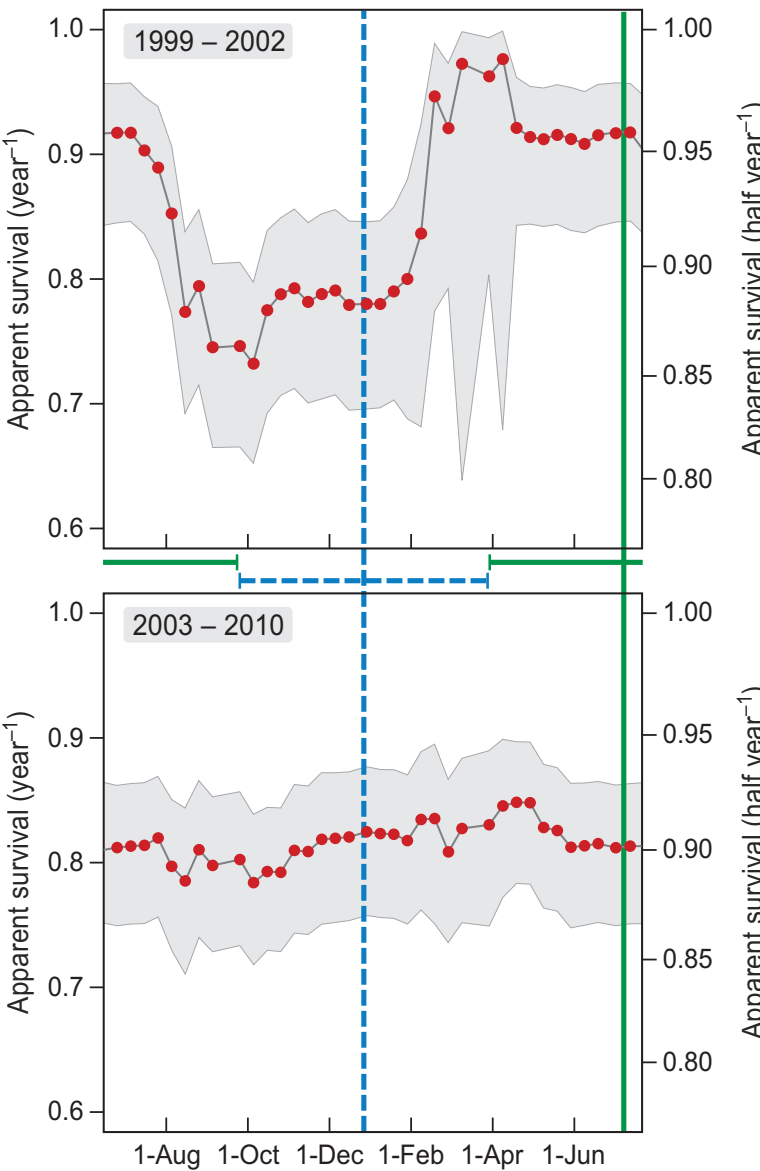

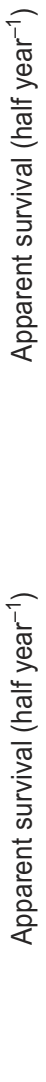

Figure 3. Seasonal apparent survival (mean with $95 \%$ confidence interval) of the islandica red knot estimated with the rolling window approach for the intense dredging (1999-2002) and the relaxation period (2003-2010). During period of intense cockle dredging in the Wadden Sea seasonal survival rates differed a lot between summer and winter but as soon as dredging stopped the pattern of seasonal survival flattened. Best pooling intervals are shown with horizontal solid green and dashed blue lines with vertical lines marking the centres.

carried out for the selected definition of seasons, which we will call 'summer' and 'winter'. All the models presented in Table 3 were run for these seasons and produced results shown in Table 4. Model averaged winter apparent survival during the cockle dredging was quite low $\left(0.78 \pm 0.04 \mathrm{yr}^{-1}\right.$, as 'seasonal survival' we report half-year survival probabilities calculated on an annual basis) comparing to summer estimates $\left(0.91 \pm 0.03 \mathrm{yr}^{-1}\right)$. During the relaxation period winter survival almost equalized with summer survival $\left(0.81 \pm 0.03 \mathrm{yr}^{-1}\right.$ and $0.82 \pm 0.03 \mathrm{yr}^{-1}$, respectively).

With an evidence ratio of 1.2 , the first prediction, that during the limitation period apparent winter survival will be lower than during the relaxation period, could not be rejected. With the evidence ratio of 8.2 , the second prediction, that during the limitation period seasonal compensation will lead to higher survival outside the limiting season, was actually highly supported by the data. Apparent survival also notably differed between seasons during the limitation period (evidence ratio of 5.4) and showed an absence of evidence for differences during the relaxation period (0.62). 
Table 4. Models of seasonal apparent survival of islandica red knot. Note: see Table 3 for the model design explanation. Time since marking (TSM) class has two levels - 'first year after marking' and 'other years'. The resighting probability was modelled as TSMclass + time. The results are adjusted for overdispersion of 1.057 (see 'Analysis'). a Deviance $=3324.55$; b Quasi corrected Akaike information criterion $\left(\mathrm{QAIC}_{\mathrm{c}}\right)=12073.21$.

\begin{tabular}{|c|c|c|c|c|}
\hline Model & $\mathrm{K}$ & $\begin{array}{c}\Delta \\
\text { deviance }\end{array}$ & $\triangle \mathrm{QAIC}_{\mathrm{c}}$ & $\begin{array}{l}\text { Model } \\
\text { weight }\end{array}$ \\
\hline$\Phi(\sim$ TSMclass + C) & 36 & $0^{\mathrm{a}}$ & $0^{\mathrm{b}}$ & 0.42 \\
\hline$\Phi(\sim$ TSMclass $+\mathrm{E})$ & 36 & 0.82 & 0.82 & 0.28 \\
\hline$\Phi(\sim$ TSMclass $+\mathrm{A})$ & 37 & -0.06 & 1.98 & 0.16 \\
\hline$\Phi(\sim$ TSMclass + F $)$ & 35 & 6.09 & 4.06 & 0.06 \\
\hline$\Phi(\sim$ TSMclass $+\mathrm{G})$ & 35 & 7.07 & 5.03 & 0.03 \\
\hline$\Phi(\sim$ TSMclass + B $)$ & 36 & 6.01 & 6.01 & 0.02 \\
\hline$\Phi(\sim$ TSMclass $+\mathrm{H})$ & 34 & 10.14 & 6.07 & 0.02 \\
\hline$\Phi(\sim$ TSMclass + D $)$ & 36 & 6.73 & 6.73 & 0.01 \\
\hline
\end{tabular}

\section{Discussion}

\section{Notes on the rolling window approach}

Despite low resighting rates, the rolling window approach that we applied converged for almost every slice. Larger sample sizes will improve the estimates for the time-independent model and will allow an estimation of a mixed effects model with year having a random effect on the survival that could be carried out either in MARK (Burnham and White 2002), ADMB (Fournier et al. 2012) or a Bayesian framework (Kéry and Schaub 2012). Due to the low resighting rates we were not able to estimate the parameters in such a mixed model. Also, ideally, seasonally changing survival should be estimated in one model rather than independently for each slice. Still, our approach provides a good exploratory tool for estimating seasonal survival rates from near-continuous data and might be considered as an important step of workflow followed by selection of the best positions of boundaries and their consequent use in the more detailed analysis.

\section{Winter and summer density dependence}

Van Gils et al. (2006) and Kraan et al. (2009) provided the arguments to show that mechanical cockle dredging in the western Dutch Wadden Sea reduced the extent of suitable intertidal feeding habitat, a loss which would have intensified competition for food and cause density-dependent responses. Our finding of a reduced apparent survival rate at the wintering grounds during this period is a quantitative confirmation that during food stock decline knot populations was limited during the winter season. Seasonal survival showed full compensation of strong winter densitydependent regulation by high survival in summer. The important point here is that compensation occurred with respect to survival, rather than with respect to the combination of survival and reproduction (Fig. 1). Also, in contrast with the apparent winter survival estimates (that might be lowered by emigration), summer survival estimates cannot be biased by immigration. An influx of unmarked animals does not affect estimates.

Where and when during February-July does density dependence operate? Boyd and Piersma (2001) studied the demography of knots wintering in the UK in 1969-1995 and proposed that away from the wintering areas density dependence may take place on three different occasions: 1) during fattening before the spring migration, 2) at the stopover sites during migration and 3) at the High Arctic breeding grounds. As red knots breed in very low densities over vast landscapes (see Boyd and Piersma 2001 for details), it is hard to believe that density-dependent mortality could occur at the breeding grounds. Survival compensations during the spring fuelling period seem much more likely. In the Wadden Sea, in early spring an important prey as Macoma balthica moves closer to the surface, thus becoming available for red knots after having been out of reach in winter (Zwarts and Wanink 1993, Piersma et al. 1994, de Goeij and Luttikhuizen 1998). Nevertheless, that knots may also be limited at migratory staging areas was documented for the rufa subspecies (Baker et al. 2004). Thus, we consider preparation for migration on the wintering areas and/or refuelling at staging sites to be candidate seasons where densitydependent mortality may compensate for loss of sufficient quality winter habitats.

\section{Seasonal compensation by sequential density dependence in adult survival}

The present estimates of the annual survival of islandica red knots $\left(0.81 \pm 0.01 \mathrm{yr}^{-1}\right)$ did not differ between the limitation and relaxation periods. This means that despite the limitation, the birds were able to actively maintain annual survival rate. Also the rates are quite similar to earlier estimates of between $0.74 \mathrm{yr}^{-1}$ and $0.79 \mathrm{yr}^{-1}$ for birds wintering in UK in 1965-1995 (Boyd and Piersma 2001) and $0.82-0.89 \mathrm{yr}^{-1}$ for birds wintering in the Wadden Sea in 1998-2002 (Kraan et al. 2009, based on part of the dataset analysed here). The estimates are also close to the apparent adult survival estimate of $0.82 \mathrm{yr}^{-1}$ for a Mauritanian winter population of the canutus subspecies that migrates between breeding grounds in northern Siberia to winter in coastal wetlands in west Africa (Leyrer et al. 2013). This similarity of survival rates in different populations and subspecies under different challenges may suggest that similar mechanisms based on sequential density dependence may be involved. This immediately begs the question whether there are limits to such density-dependent compensation? In other words: are any negative changes in one part of the flyway always being compensated in the other parts? The amount of possible compensation by seasonal compensation has obvious limits. As annual survival is a product of summer and winter 
survival $\left(S_{\text {annual }}=S_{\text {summer }} \times S_{\text {winter }}\right)$ and as neither of the seasons could show survival over 1, in order to maintain annual survival, the survival in the limiting season cannot be lower than the annual survival. For example, let annual survival be 0.81 . If winter survival would be less than 0.81 , than summer survival should be greater than 1 to compensate towards the annual survival of 0.81 .

\section{Sequential density dependence in a meta-population context}

Islandica red knots wintering in the Wadden Sea are in fact part of a large meta-population that includes birds wintering in the other parts of the Wadden Sea and also UK and France. Densities across wintering areas followed the ideal free distribution (IFD, Quaintenne et al. 2011). Being globally optimal, IFD in meta-population may be reached by local demographic processes and/or movements (Křivan et al. 2008). These two processes are quite similar and complementary both in bringing a population to the global optimum (Cressman and Křivan 2006), and in being hard to distinguish from the perspective of data analysis. For the islandica knot, van Gils et al. (2006) suggested that a decrease in resighting rates and in the nonbreeding in the Dutch Wadden Sea was caused by either mortality or permanent emigration. Using a CJS model, Bijleveld et al. (2014) were able to distinguish between apparent survival (including permanent emigration) and temporary emigration, and showed that the observations of van Gils et al. were likely explained by temporary emigration of birds with small gizzards (this part of the digestive machinery is critical for foraging performance in the molluscivore shorebird, van Gils et al. 2003).

Theoretical considerations (Dolman and Sutherland 1995) indicated that the loss of one of several shared wintering sites may indeed be buffered by neighbouring areas. The rate in which a population will be able to rely on alternatives depends on how often individuals move between wintering sites (Cressman and Krrivan 2006), on the cost of this movement (Cressman and Křivan 2006) and on the flexibility of the movement routines (Dolman and Sutherland 1995, Piersma 2011, Verkuil et al. 2012). Islandica knots seem to keep relatively strong connections even between remote wintering sites (from 3048 colour-marked birds 40 were seen the same season in both the UK and the Wadden Sea), and to incur relatively low cost for these movements (Quaintenne et al. 2011), so they are likely to adapt fast to the specific changes at some parts of the wintering area. Generally, being part of a geographically extended metapopulation has helped red knot through the bad times in the Dutch Wadden Sea and could help other species with similar multiple 'density-dependent process areas' to cope with rapidly changing ecological conditions.

\section{Decline despite compensation?}

Why did the locally wintering knot population show a decline during a period of food shortage in the Dutch Wadden Sea (Kraan et al. 2009), while in these years overall annual survival was the same as during the recovery? We see three possible explanations here: 1) temporal emigration, 2) low reproduction or 3) low juvenile to adult survival. We have discussed above that knots could temporarily emigrate from the Wadden Sea to other wintering sites and come back during the relaxation period (note that the CJS model will accounts for such temporal emigration by lowering estimated resighting rate, providing thus an unbiased estimate of survival). A second possible reason for the unexplained decline in the population numbers is a decline in reproduction or juvenile survival (Fig. 1). If there are cross-seasonal trade-offs between current reproduction and subsequent survival (i.e. carry-over effects), reproduction efforts may be reduced after a harsh winter to ensure survival. A third possibility is that density-dependent mortality in winter operates jointly on juveniles and adults, but involves juveniles to a greater extent. In knots, juveniles are out-competed by adults (van den Hout et al. 2014) and thus could suffer high mortality during the winter. Unfortunately, a lack of counts of juveniles makes it currently impossible to investigate these last two hypotheses.

\section{Evolution of seasonal survival patterns}

One of the striking results of this study is that during the relaxation period we observed a flattening of the seasonal adult survival curve. This is in concordance with findings for relaxed (under equilibrium) populations, such as greater snow geese Chen caerulescens atlantica (Gauthier et al. 2001) and European spoonbills Platalea leucorodia (Lok et al. 2013). Following Carlson et al. (2008), we suggest that evenly distributed annual mortality might in fact be a general pattern for an adapted population at equilibrium. This is because any excess (seasonal) mortality will cause directional selection towards the minimization of that excess. To illustrate this point, we plotted population size against time of the year (Fig. 4A) and then introduced a new disturbance: a season $t_{1}$ with an increased mortality rate (Fig. $4 \mathrm{~B}$ ). This disturbance created two stabilizing forces that would help the population to adapt to the changed environment. The first force ('current pressure') is a direct function of differential mortality, as an increase in mortality will encourage adaptive responsiveness independent of density-dependent or independent mortality sources by means of phenotypic adjustments at the level of physiology (Boyce 1979), bodily constitution and behaviour (Piersma and van Gils 2011), and/or distribution (Dolman and Sutherland 1995, Rakhimberdiev et al. 2011). The second force ('released pressure') is a consequence of released density dependence after the peak mortality event - seasonal compensation (Boyce et al. 1999). At $t_{2}$ density becomes low, making densitydependent mortality and selection pressures also low. Lowered selection pressure at $t_{2}$ may facilitate adaptation at $t_{1}$ if the released adaptation potential at $t_{2}$ can be used at $t_{1}$ (obviously, due to cyclic character of seasons, $t_{1}$ both follows and precedes $t_{2}$ ). Thus, the proposed evolutionary forces will smooth out the mortality effects of the harsh season. If specific unsolvable trade-offs in survival between seasons do not occur, they might even equalize adult mortality completely.

Our results, together with such an evolutionary perspective, challenge the idea that each population has its maximum mortality during a particular part of year, the so-called 'bottleneck' season (Piersma 2002, Buehler and Piersma 

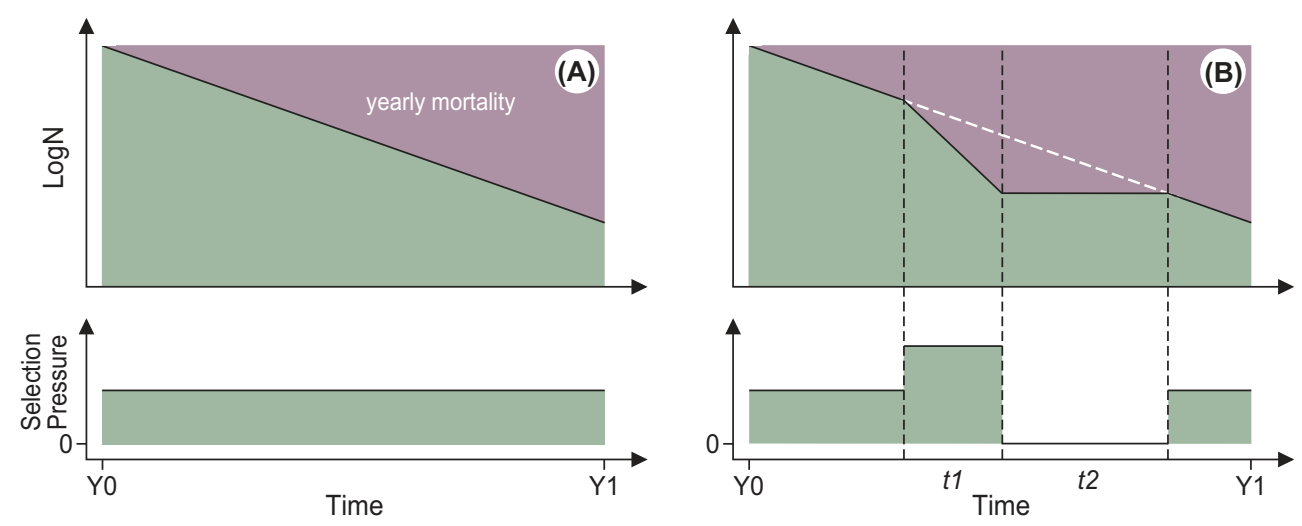

Figure 4. A theoretical model of the distribution of adult mortality in the course of a year. The fully adapted population under equilibrium (A) shows an evenly distributed mortality. Panel (B) shows that high mortality due to changed conditions in a season $\left(t_{1}\right.$ in B) induces a release in selection pressure by two forces: 1 ) a 'current pressure' force at $t_{1}$ will speed up the adaptation to a new condition; 2) a 'released force' at $t_{2}$ may produce additional impetus for that adaptation.

2008). Instead, we now argue that, rather than occurring in an (ecologically determined) fixed part of the season, 'survival bottlenecks' might arise from environmental change. A bottleneck temporarily concentrates mortality at a changed place and/or time. Being at least partially differential, the mortality will intensify natural selection. In absence of specific trade-offs the forces of natural selection should wane when the population reaches a state of adjustment. Thus, a 'bottleneck' should be re-defined as a 'temporary change in mortality rate during the annual cycle in a population enforcing adjustments to changed environmental conditions'.

\section{Conclusion}

Sequential density dependence in local survival and the apparently low costs of emigration allowed the islandica red knots wintering in the Dutch Wadden Sea to overcome a critical phase of human habitat overexploitation by moving away to other areas in north-western Europe. This means that at this spatial scale the alternative areas had enough habitat of sufficient quality, red knots were flexible enough, and that at the time the islandica knot population must have been below overall carrying capacity. Sequential density dependence might thus buffer the effects of some environmental limitations but only up to some level. Measures of annual apparent survival are likely to be smoothed by seasonal compensation and thus are much less efficient as an 'early warning' signal than seasonal survival measurements.

Acknowledgements - We thank the late Piet Duiven, as well as Anne Dekinga, Casper Kraan, Sander Holthuijsen, Job ten Horn, and many others (often as volunteers) for assistance with the catching and colour-marking. A large number of dedicated volunteers and professionals contributed to ring reading, particularly Harry Horn, Laurens van Kooten, Christophe Brochard, Dick Schermer, Job ten Horn, Allert Bijleveld, Jelle Loonstra, Otto Overdijk, and Tom van Spanje. The crews of Royal NIOZ-research vessel RV Navicula made major contributions to the field work. The ideas of the manuscript were developed in fruitful discussions with, and constructive feedback from, Stephen Ellner, Ian Newton, Julia Karagicheva, Jesse Conklin, Tamar Lok, Nathan Senner, Yvonne Verkuil and
Steffen Oppel. Dick Visser made the final figures. This research has been supported by a PIONIER-grant to TP in 1996-2002, operational grants from NIOZ in 2002-2012, and by the Metawad grant from (WF 209925) Waddenfonds in 2012-2014.

\section{References}

Alerstam, T. 1990. Bird migration. - Cambridge Univ. Press.

Alerstam, T. and Högstedt, G. 1982. Bird migration and reproduction in relation to habitats for survival and breeding. - Ornis Scand. 13: 25.

Anderson, D. R. and Burnham, K. P. 1976. Population ecology of the mallard: VI. The effect of exploitation on survival. - United States Fish and Wildlife Service Resource Publication 128.

Baker, A. J., Piersma, T. and Greenslade, A. D. 1999. Molecular vs. phenotypic sexing in red knots. - Condor 101: 887-893.

Baker, A. J., Gonzalez, P. M., Piersma, T., Niles, L. J., Atkinson, P. W., Clark, N. A., Minton, C. D. T., Peck, M. K., de Lima Serrano do Nascimento, I. and Aarts, G. 2004. Rapid population decline in red knots: fitness consequences of decreased refuelling rates and late arrival in Delaware Bay. - Proc. R. Soc. B 271: 875-882.

Bijleveld, A. I., Massourakis, G., van der Marel, A., Dekinga, A., Spaans, B., van Gils, J. A. and Piersma, T. 2014. Personality drives physiological adjustments and is not related to survival. - Proc. R. Soc. B 281: 20133135.

Boere, G. C. 1976. The significance of the Dutch Waddenzee in the annual life cycle of arctic, subarctic and boreal waders. Part 1. The function as a moulting area. - Ardea 64: 210-291.

Boyce, M. S. 1979. Seasonality and patterns of natural selection for life histories. - Am. Nat. 114: 569.

Boyce, M. S., Sinclair, A. and White, G. C. 1999. Seasonal compensation of predation and harvesting. - Oikos 87: 419-426.

Boyd, H. and Piersma, T. 2001. Changing balance between survival and recruitment explains population trends in red knots Calidris canutus islandica wintering in Britain, 1969-1995. - Ardea 89: 301-317.

Brochard, C., Spaans, B., Prop, J. and Piersma, T. 2002. Use of individual colour-ringing to estimate annual survival in male and female red knot Calidris canutus islandica: a progress report for 1998-2001. - Wader Study Group Bull. 99: $54-56$.

Buehler, D. M. and Piersma, T. 2008. Travelling on a budget: predictions and ecological evidence for bottlenecks in the 
annual cycle of long-distance migrants. - Phil. Trans. R. Soc. B 363: 247-266.

Burnham, K. P. and Anderson, D. R. 1984. Tests of compensatory vs. additive hypotheses of mortality in mallards. - Ecology 65 : 105-112.

Burnham, K. P. and Anderson, D. R. 2002. Model selection and multi-model inference: a practical information-theoretic approach. - Springer

Burnham, K. P. and White, G. C. 2002. Evaluation of some random effects methodology applicable to bird ringing data. - J. Appl. Stat. 29: 245-264.

Carlson, S. M., Olsen, E. M. and Vøllestad, L. A. 2008. Seasonal mortality and the effect of body size: a review and an empirical test using individual data on brown trout. - Funct. Ecol. 22: 663-673.

Cleveland, W. S. 1979. Robust locally weighted regression and smoothing scatterplots. - J. Am. Stat. Assoc. 74: 829-836.

Compton, T. J., Holthuijsen, S., Koolhaas, A., Dekinga, A., ten Horn, J., Smith, J., Galama, Y., Brugge, M., van der Wal, D., van der Meer, J., van der Veer, H. W. and Piersma, T. 2013. Distinctly variable mudscapes: distribution gradients of intertidal macrofauna across the Dutch Wadden Sea. - J. Sea Res. 82: 103-116.

Cressman, R. and Křivan, V. 2006. Migration dynamics for the ideal free distribution. - Am. Nat. 168: 384-397.

Davidson, N. 2002. Red knot (knot) Calidris canutus. - In: Wernham, C. et al. (eds), The migration atlas: movements of the birds of Britain and Ireland. Poyser, pp. 293-296.

Davidson, N. and Wilson, J. 1992. The migration system of European-wintering knots Calidris canutus islandica. - Wader Study Group Bull. 64: 39-51.

de Goeij, P. and Luttikhuizen, P. 1998. Deep-burying reduces growth in intertidal bivalves: field and mesocosm experiments with Macoma balthica. - J. Exp. Mar. Biol. Ecol. 228: 327-337.

Dietz, M. W., Spaans, B., Dekinga, A., Klaassen, M., Korthals, H., van Leeuwen, C. and Piersma, T. 2010. Do red knots (Calidris canutus islandica) routinely skip Iceland during southward migration? - Condor 112: 48-55.

Dietz, M. W., Rogers, K. G. and Piersma, T. 2013. When the seasons don't fit: speedy molt as a routine carry-over cost of reproduction. - PLoS One 8: e53890.

Dolman, P. M. and Sutherland, W. J. 1995. The response of bird populations to habitat loss. - Ibis 137(S1): 38-46.

Eriksson, B. K., van der Heide, T., van de Koppel, J., Piersma, T., van der Veer, H. W. and Olff, H. 2010. Major changes in the ecology of the Wadden Sea: human impacts, ecosystem engineering and sediment dynamics. - Ecosystems 13: 752-764.

Faaborg, J., Holmes, R. T., Anders, A. D., Bildstein, K. L., Dugger, K. M., Gauthreaux, S. A., Heglund, P., Hobson, K. A., Jahn, A. E., Johnson, D. H., Latta, S. C., Levey, D. J., Marra, P. P., Merkord, C. L., Nol, E., Rothstein, S. I., Sherry, T. W., Sillett, T. S., Thompson, F. R. and Warnock, N. 2010. Conserving migratory land birds in the New World: do we know enough? - Ecol. Appl. 20: 398-418.

Fournier, D. A., Skaug, H. J., Ancheta, J., Ianelli, J., Magnusson, A., Maunder, M. N., Nielsen, A. and Sibert, J. 2012. AD Model Builder: using automatic differentiation for statistical inference of highly parameterized complex nonlinear models. - Optim. Methods Softw. 27: 233-249.

Fretwell, S. D. 1972. Populations in a seasonal environment. - Princeton Univ. Press.

Gauthier, G., Pradel, R., Menu, S. and Lebreton, J.-D. 2001. Seasonal survival of greater snow geese and effect of hunting under dependence in sighting probability. - Ecology 82: 3105.

Hargrove, J. and Borland, C. 1994. Pooled population parameter estimates from mark-recapture data. - Biometrics 50: 1129-1141.
Herrando-Pérez, S., Delean, S., Brook, B. W. and Bradshaw, C. J. A. 2012. Density dependence: an ecological Tower of Babel. - Oecologia 170: 585-603.

Kéry, M. and Schaub, M. 2012. Bayesian population analysis using WinBUGS a hierarchical perspective. - Academic Press.

Kittle, A. M., Fryxell, J. M., Desy, G. E. and Hamr, J. 2008. The scale-dependent impact of wolf predation risk on resource selection by three sympatric ungulates. - Oecologia 157: 163-175.

Kokko, H. and Lindström, J. 1998. Seasonal density dependence, timing of mortality, and sustainable harvesting. - Ecol. Model. 110: 293-304.

Kraan, C., Piersma, T., Dekinga, A., Koolhaas, A. and van der Meer, J. 2007. Dredging for edible cockles (Cerastoderma edule) on intertidal flats: short-term consequences of fisher patch-choice decisions for target and non-target benthic fauna. - ICES J. Mar. Sci. 64: 1735-1742.

Kraan, C., van Gils, J. A., Spaans, B., Dekinga, A., Bijleveld, A. I., van Roomen, M., Kleefstra, R. and Piersma, T. 2009. Landscape-scale experiment demonstrates that Wadden Sea intertidal flats are used to capacity by molluscivore migrant shorebirds. - J. Anim. Ecol. 78: 1259-1268.

Kraan, C., Dekinga, A. and Piersma, T. 2010. Now an empty mudflat: past and present benthic abundances in the western Dutch Wadden Sea. - Helgol. Mar. Res. 65: 51-58.

Křivan, V., Cressman, R. and Schneider, C. 2008. The ideal free distribution: a review and synthesis of the game-theoretic perspective. - Theor. Popul. Biol. 73: 403-425.

Laake, J. L. 2013. RMark: an R interface for analysis of capturerecapture data with MARK. - AFSC Processed Rep. 2013-01, Alaska Fish. Sci. Cent. NOAA, Natl. Mar. Fish. Serv.

Laake, J. L., Johnson, D. S. and Conn, P. B. 2013. marked: an R package for maximum likelihood and Markov Chain Monte Carlo analysis of capture-recapture data. - Methods Ecol. Evol. 4: 885-890.

Lebreton, J.-D., Burnham, K. P., Clobert, J. and Anderson, D. R. 1992. Modeling survival and testing biological hypotheses using marked animals: a unified approach with case studies. - Ecol. Monogr. 62: 67-118.

Leyrer, J., Lok, T., Brugge, M., Spaans, B., Sandercock, B. K. and Piersma, T. 2013. Mortality within the annual cycle: seasonal survival patterns in Afro-Siberian red knots Calidris canutus canutus. - J. Ornithol. 154: 933-943.

Lok, T., Overdijk, O., Tinbergen, J. and Piersma, T. 2013. Seasonal variation in density dependence in age-specific survival of a long-distance migrant. - Ecology 94: 2358-2369.

Norris, D. R. 2005. Carry-over effects and habitat quality in migratory populations. - Oikos 109: 178-186.

Norris, D. R., Marra, P. P., Kyser, T. K., Sherry, T. W. and Ratcliffe, L. M. 2004. Tropical winter habitat limits reproductive success on the temperate breeding grounds in a migratory bird. - Proc. R. Soc. B 271: 59-64.

O’Brien, S., Robert, B. and Tiandry, H. 2005. Consequences of violating the recapture duration assumption of markrecapture models: a test using simulated and empirical data from an endangered tortoise population. - J. Appl. Ecol. 42: 1096-1104.

Oppel, S., Hilton, G., Ratcliffe, N., Fenton, C., Daley, J., Gray, G., Vickery, J. and Gibbons, D. 2014. Assessing population viability while accounting for demographic and environmental uncertainty. - Ecology 95: 1809-1818.

Piersma, T. 2002. Energetic bottlenecks and other design constraints in avian annual cycles. - Integr. Comp. Biol. 42: $51-67$.

Piersma, T. 2011. Flyway evolution is too fast to be explained by the modern synthesis: proposals for an "extended" evolutionary research agenda. - J. Ornithol. 152: 151-159.

Piersma, T. 2012. What is habitat quality? Dissecting a research portfolio on shorebirds. - In: Fuller, R. J. (ed.), Birds and 
habitat: relationships in changing landscapes. Ecological reviews. Cambridge Univ. Press, pp. 383-407.

Piersma, T. and van Gils, J. A. 2011. The flexible phenotype: a body-centred integration of ecology, physiology, and behaviour. - Oxford Univ. Press.

Piersma, T., Hoekstra, R., Dekinga, A., Koolhaas, A., Wolf, P., Battley, P. and Wiersma, P. 1993. Scale and intensity of intertidal habitat use by knots Calidris canutus in the western Wadden Sea in relation to food, friends and foes. - Neth. J. Sea Res. 31: 331-357.

Piersma, T., Verkuil, Y. and Tulp, I. 1994. Resources for longdistance migration of knots Calidris canutus islandica and C. c. canutus: how broad is the temporal exploitation window of benthic prey in the western and eastern Wadden Sea? - Oikos 71: 393

Piersma, T., Koolhaas, A., Dekinga, A., Beukema, J. J., Dekker, R. and Essink, K. 2002. Long-term indirect effects of mechanical cockle-dredging on intertidal bivalve stocks in the Wadden Sea. - J. Appl. Ecol. 38: 976-990.

Piersma, T., Rogers, D. I., González, P. M., Zwarts, L., Niles, L. J., de Lima Serrano do Nascimento, I., Minton, C. D. T. and Baker, A. J. 2005. Fuel storage rates before northward flights in red knots worldwide. - In: Greenberg, R. and Marra, P. P. (eds), Birds of Two Worlds: the ecology and evolution of migration. Johns Hopkins Univ. Press, pp. 262-273.

Quaintenne, G., van Gils, J. A., Bocher, P., Dekinga, A. and Piersma, T. 2011. Scaling up ideals to freedom: are densities of red knots across western Europe consistent with ideal free distribution? - Proc. R. Soc. B 278: 2728-2736.

Rakhimberdiev, E., Verkuil, Y. I., Saveliev, A. A., Väisänen, R. A., Karagicheva, J., Soloviev, M. Y., Tomkovich, P. S. and Piersma, T. 2011. A global population redistribution in a migrant shorebird detected with continent-wide qualitative breeding survey data: eastward redistribution of Arctic breeding ruffs. - Divers. Distrib. 17: 144-151.

Runge, M. C. and Marra, P. P. 2005. Modeling seasonal interactions in the population dynamics of migratory birds. - In: Greenberg, R. and Marra, P. P. (eds), Birds of two worlds: the ecology and evolution of migration. Johns Hopkins Univ. Press, pp. 375-389.
Schaub, M., Reichlin, T. S., Abadi, F., Kéry, M., Jenni, L. and Arlettaz, R. 2012. The demographic drivers of local population dynamics in two rare migratory birds. - Oecologia 168: 97-108

Tempel, D. J., Peery, M. Z. and Gutiérrez, R. J. 2014. Using integrated population models to improve conservation monitoring: California spotted owls as a case study. - Ecol. Model. 289: 86-95.

van den Hout, P. J., van Gils, J. A., Robin, F., van der Geest, M., Dekinga, A. and Piersma, T. 2014. Interference from adults forces young red knots to forage for longer and in dangerous places. - Anim. Behav. 88: 137-146.

van Gils, J. A., Piersma, T., Dekinga, A. and Dietz, M. W. 2003. Cost-benefit analysis of mollusc-eating in a shorebird II. Optimizing gizzard size in the face of seasonal demands. - J. Exp. Biol. 206: 3369-3380.

van Gils, J. A., Piersma, T., Dekinga, A., Spaans, B. and Kraan, C. 2006. Shellfish dredging pushes a flexible avian top predator out of a marine protected area. - PLoS Biol. 4: 2399-2404.

Verkuil, Y. I., Karlionova, N., Rakhimberdiev, E. N., Jukema, J., Wijmenga, J. J., Hooijmeijer, J. C. E. W., Pinchuk, P., Wymenga, E., Baker, A. J. and Piersma, T. 2012. Losing a staging area: eastward redistribution of Afro-Eurasian ruffs is associated with deteriorating fuelling conditions along the western flyway. - Biol. Conserv. 149: 51-59.

White, G. C. and Burnham, K. P. 1999. Program MARK: survival estimation from populations of marked animals. - Bird Study 46: S120-S139.

Wilson, J., Dick, W. J. A., Jackson, D., Jackson, L., Lenton, G., Soot, K. M., Stanyard, D., Strugnell, R., Swinfen, B. J., Swinfen, R. C. and Wilson, R. 2009. The migration of red knots through Porsangerford in spring 2009: a progress report on the Norwegian Knot Project. - Wader Study Group Bull. 116: $160-166$.

Zwarts, L. and Wanink, J. H. 1993. How the food supply harvestable by waders in the Wadden Sea depends on the variation in energy density, body weight, biomass, burying depth and behaviour of tidal-flat invertebrates. - Neth. J. Sea Res. 31: $441-476$. 